\title{
An anatomic study of the lateral femoral cutaneous nerve in human fetuses*
}

\author{
Zeliha Fazlıŏulları ${ }^{1}$ İ́smihan İlknur Uysal ${ }^{1}$, Nadire Ünver Doğan ${ }^{1}$, \\ Ahmet Kağan Karabulut ${ }^{1}$, Taner Ziylan ${ }^{2}$ \\ ${ }^{1}$ Department of Anatomy, Faculty of Medicine, Selçuk University, Konya, Turkey \\ ${ }^{2}$ Department of Anatomy, Faculty of Medicine, KTO Karatay University, Konya, Turkey
}

\begin{abstract}
Objectives: The aim of the study was to determine the anatomic course of the lateral femoral cutaneous nerve (LFCN) and its branches in relation to certain anatomic landmarks in human fetuses.

Methods: This study was performed on 50 thighs from 25 spontaneously aborted fetuses with no detectable malformations. The LFCN position was evaluated according to its relation to the anterior superior iliac spine and its distance from the femoral nerve and femoral artery were measured along the inguinal ligament (IL). The relationship between the LFCN and femoral nerve in the pelvic cavity was also evaluated.

Results: The branching pattern of the nerve was classified according to number and branching location of the main trunk as: Type I, a single trunk; Type II, two trunks, Type III;: three trunks, and Type IV: LFCN branching above or behind the IL. Sub-types of the LFCN were determined in accordance with the number of branches of the main trunk. Up to four branches of the LFCN were found; two branches originating from a single trunk was the most common type (54\%). The most common site of the LFCN was observed nearly adjacent to the anterior superior iliac spine. In 11 lower limbs, the femoral nerve was accompanying with the LFCN on its course in pelvic cavity.

Conclusion: The results of this study on the morphological features and variations of the LFCN in fetuses provide understanding of its variability for further studies in the region.
\end{abstract}

Keywords: branching pattern; fetus; lateral femoral cutaneous nerve; meralgia paresthetica

Anatomy 2016;10(1):16-20 @2016 Turkish Society of Anatomy and Clinical Anatomy (TSACA)

\section{Introduction}

The lateral femoral cutaneous nerve (LFCN) is purely a sensory nerve, arising from the posterior divisions of the anterior rami of L2 and L3 spinal nerves. ${ }^{[1]}$ The left nerve passes behind the lower part of the descending colon. Both nerves pass behind or through the inguinal ligament (IL) about $1 \mathrm{~cm}$ medial to the anterior superior iliac spine (ASIS) and anterior to or through the sartorius muscle into the thigh. ${ }^{[2]}$ Then, the nerve classically divides into anterior and posterior branches on the ante- rior surface of the sartorius muscle. The anterior branch is distributed to the skin of the anterior and lateral parts of the thigh, as far as inferiorly to the knee. The posterior branch divides into filaments on the lateral surface of the limb to supply the skin from the greater trochanter to about the mid-thigh. It may also supply twigs to the skin of the gluteal region. ${ }^{[2,3]}$

Although variable courses of the LFCN have been reported ${ }^{[4-6]}$ the most common course is observed medial to the ASIS. During the ilioinguinal surgical approaches to the pelvis, the course of the LFCN and its branching

*This study was presented at The International Anatomical Sciences and Cell Biology Conference, May 26-29, 2010, Singapore 
pattern are crucial for avoiding nerve injury. ${ }^{[7]}$ Therefore, the aim of this study was to determine the anatomic course of the LFCN and its branches in relation to certain anatomic landmarks.

\section{Materials and Methods}

This study was performed on 50 lower limbs (left and right sides) of 25 (12 males, 13 females) spontaneously aborted fetuses without any detectable malformations, from the collection of the Department of Anatomy of Selçuk University. The study complied with the ethical standards of the responsible committee on human experimentation of the Selçuk University School of Medicine Human Research Ethics Committee, in accordance to the Helsinki Declaration. Fetuses were fixed by immersion in $10 \%$ formalin. The age of the fetuses were determined on the basis of crown-rump length (CRL) measurements and ranged between the 15 th to 35 th postmenstrual weeks. The fetuses were divided according to gestational age into two groups: second trimester group of 17 cases, and third trimester group of 8 cases. There were no first trimester fetuses among our samples.

Incisions were made on the IL on a line extending from the ASIS to the pubic tubercle, and on the anterior thigh on a line extending from the midpoint of the IL to the medial aspect of the knee. The dissection started by removing the skin, and proceeding deeper. The course of the LFCN and its branching patterns were traced.

The position of the LFCN was evaluated according to its relation to ASIS and distances from the femoral nerve $(\mathrm{FN})$ and femoral artery (FA) were measured along the IL. The relationship between the LFCN and femoral nerve in the pelvic cavity was also examined. Chi square and MannWhitney $U$ tests were performed to compare the groups and measurements in relation to age and gender.

\section{Results}

In all extremities, LFCN entered the thigh by passing behind the IL and supplied the skin of the thigh. The branching pattern of the nerve was classified according to the number and branching location of the main trunks: Type I: single trunk, Type II: two trunks, Type III: three trunks, Type IV: LFCN branches above the IL or behind the IL. Subtypes of the LFCN were determined according to the number of branches of the main trunks (Figure 1).

In 41 (82\%) extremities, the LFCN passed behind the IL as a single trunk and then descended subcutaneously as a single branch or divided into two or three branches (Type I). In 7 (14\%) extremities, the LFCN divided into two trunks behind the IL, and later the posterior branch subdivided into two or three branches (Type II). In two (4\%) extremities, the LFCN divided into three trunks behind the IL and these trunks continued to innervate the skin of the thigh (Type III). In one case (2\%), the nerve divided into two branches above the IL in the iliac fossa (Type IV) (Figure 2).

The branching types of LFCN according to gender and side are shown in Table 1. Up to four branches of the

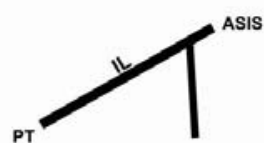

Type la (14\%)

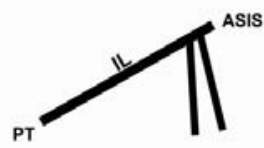

Type lla $(8 \%)$

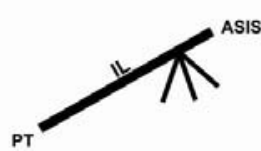

Type III (4\%)

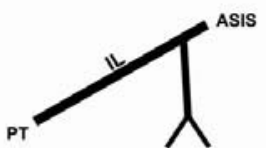

Type Ib (54\%)

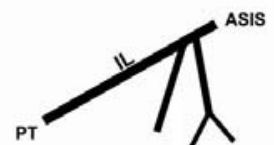

Type Ilb (2\%)

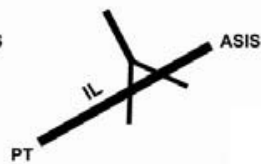

Type IV (2\%)

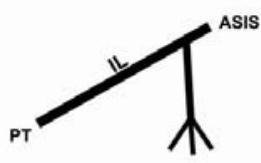

Type Ic $(14 \%)$

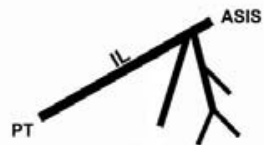

Type Ilc (2\%)
Figure 1. Schematic illustration of the branching patterns of the LFCN. ASIS: anterior superior iliac spine; IL: inguinal ligament; PT: pubic tubercle.

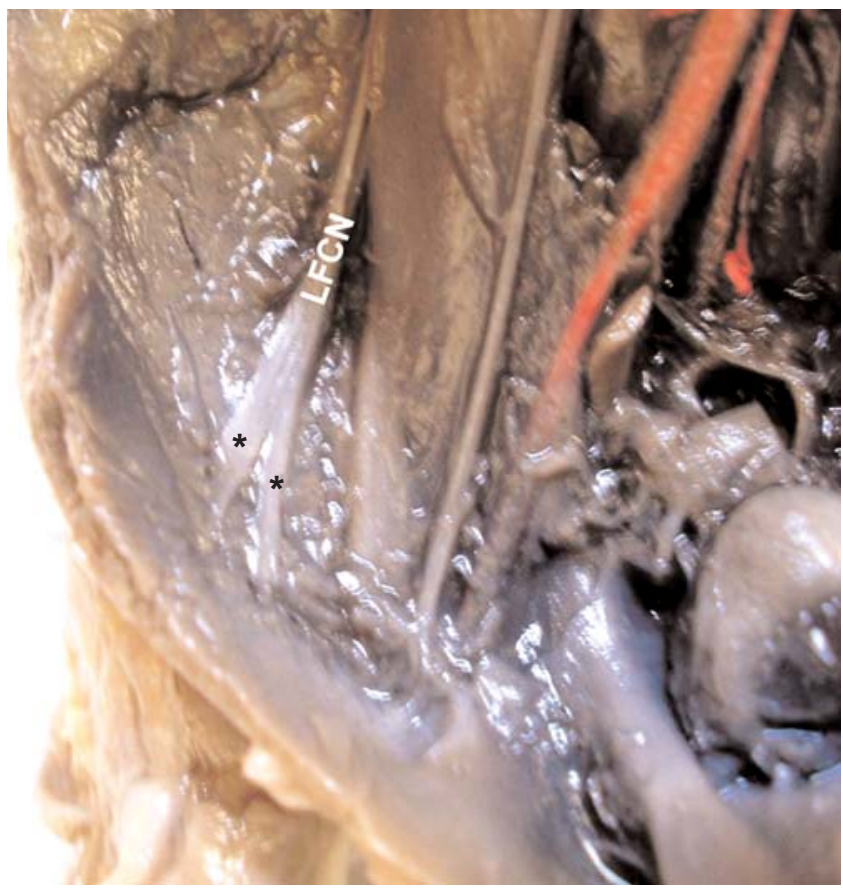

Figure 2. LFCN branching above the inguinal ligament in iliac fossa. LFCN: lateral femoral cutaneous nerve. [Color figure can be viewed in the online issue, which is available at www.anatomy.org.tr] 
Table 1

Incidence of the branching patterns of the LFCN according to gender and side.

\begin{tabular}{|c|c|c|c|c|c|c|c|c|c|c|}
\hline \multirow[t]{2}{*}{ Gender } & \multirow{2}{*}{$\begin{array}{l}\text { Case } \\
\text { (n) }\end{array}$} & \multirow[t]{2}{*}{ Side } & \multicolumn{3}{|c|}{ Type I } & \multicolumn{3}{|c|}{ Type II } & \multirow[t]{2}{*}{ Type III } & \multirow[t]{2}{*}{ Type IV } \\
\hline & & & $a$ & b & c & a & b & c & & \\
\hline \multirow[t]{2}{*}{ Male } & 24 & Right & 1 & 8 & 1 & 1 & - & 1 & - & 1 \\
\hline & & Left & 2 & 5 & 2 & 1 & - & - & 1 & - \\
\hline \multirow[t]{2}{*}{ Female } & 26 & Right & - & 9 & 2 & 1 & 1 & - & - & - \\
\hline & & Left & 4 & 5 & 2 & 1 & - & - & 1 & - \\
\hline Total & 50 & & \multicolumn{3}{|c|}{41 (82\%) } & \multicolumn{3}{|c|}{$6(12 \%)$} & $2(4 \%)$ & $1(2 \%)$ \\
\hline
\end{tabular}

LFCN were found; two branches originating from the single trunk (Type Ib) was the most common type (54\%) (Figure 3). The most common location of LFCN was found to be adjacent to the medial aspect of ASIS, behind the IL.

LFCN coursed with an average distance of $4.3 \pm 2.62$ $\mathrm{mm}$ to the femoral nerve and an average distance of $7.25 \pm 2.49 \mathrm{~mm}$ to the femoral artery along the IL. For the main branching pattern of LFCN, no significant difference was found between the sub-types of LFCN for the second and third trimester groups using Chi square test. For the distance of LFCN to the FA and FN, a significant difference was found between the second and third trimester groups $(\mathrm{p}=0.001$ and $\mathrm{p}=0.002$, respectively). No significant difference was found for gender using MannWhitney U test (Table 2).

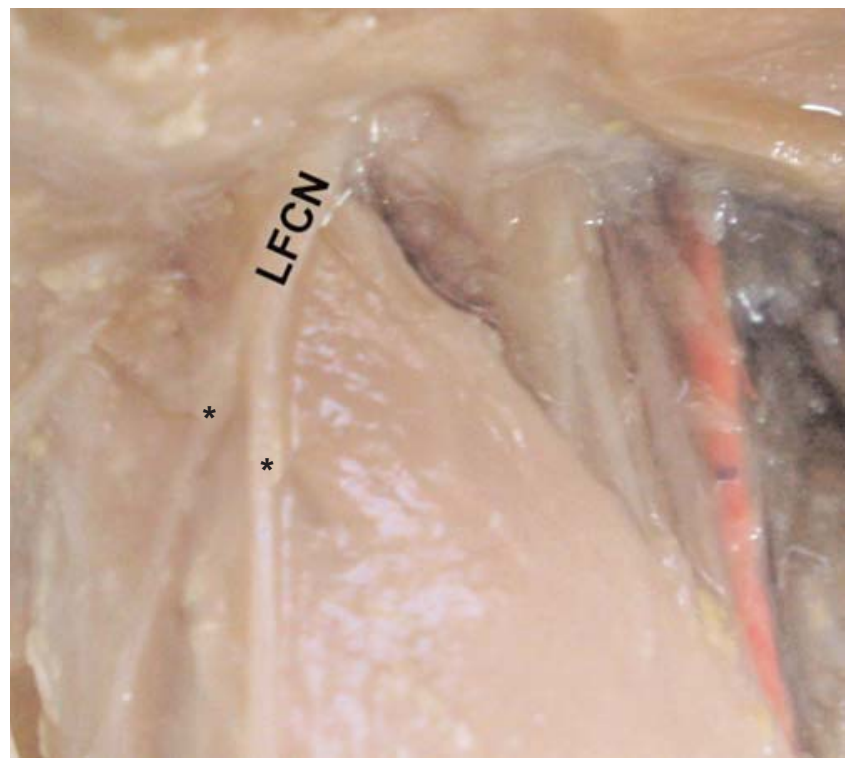

Figure 3. The nerve gaves off two branches from the main trunk (the most common type). LFCN: lateral femoral cutaneous nerve. [Color figure can be viewed in the online issue, which is available at www.anatomy.org.tr]
A close relationship between LFCN and femoral nerve was observed in 11 sides, along their courses inside the pelvis cavity up to IL (Figure 4). For the rest of the cases (39 sides), LFCN was distant from the femoral nerve in the pelvis cavity.

\section{Discussion}

The LFCN is a sensory nerve innervating the lateral and upper parts of the thigh. ${ }^{[3]}$ Meralgia paresthetica is altered sensation of the LFCN that has clinical manifestations including numbness, burning, itching, or pain over the anterior and lateral parts of the thigh. ${ }^{[8,9]}$ Iatrogenic injury of the LFCN can occur during surgery or due to the circumstances of a trauma to the ilium, usually by accidents. A cadaveric dissection study reported that the risk of dam-

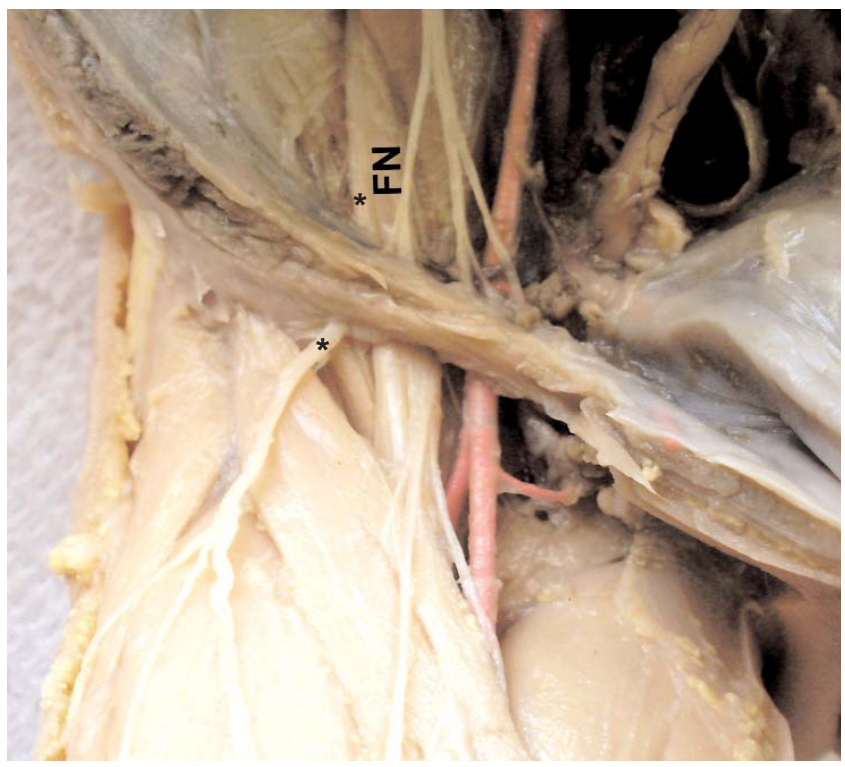

Figure 4. LFCN accompanying the femoral nerve in the pelvic cavity. *Course of the lateral femoral cutaneous nerve; FN: femoral nerve. [Color figure can be viewed in the online issue, which is available at www.anatomy.org.tr] 
Table 2

Distance of LFCN from the femoral nerve (FN) and femoral artery (FA) in relation to gender and gestational age (GA).

\begin{tabular}{|c|c|c|c|c|c|c|c|}
\hline & \multirow[t]{2}{*}{ Gender } & \multirow{2}{*}{$\begin{array}{l}\text { Fetus } \\
\text { (n) }\end{array}$} & \multirow{2}{*}{$\begin{array}{c}\text { GA } \\
\text { (Min-Max) }\end{array}$} & \multicolumn{2}{|c|}{ Distance from FN } & \multicolumn{2}{|c|}{ Distance from FA } \\
\hline & & & & Mean \pm SD & Min-Max & Mean \pm SD & Min-Max \\
\hline \multirow[t]{2}{*}{ Second trimester } & Male & 7 & $15-26$ & $3.05 \pm 1.82$ & $0-6.22$ & $5.37 \pm 1.50$ & $2.83-7.47$ \\
\hline & Female & 10 & $15-26$ & $3.80 \pm 2.75$ & $0-7.97$ & $7.12 \pm 1.29$ & $2.12-10.35$ \\
\hline \multirow[t]{2}{*}{ Third trimester } & Male & 5 & $27-35$ & $5.66 \pm 2.31$ & $0-7.74$ & $8.86 \pm 1.99$ & $5.75-11.16$ \\
\hline & Female & 3 & $27-34$ & $6.59 \pm 2.27$ & $2.47-9.19$ & $9.36 \pm 1.93$ & $5.82-11.17$ \\
\hline Total & & 25 & $15-35$ & $4.3 \pm 2.62$ & $0-9.19$ & $7.25 \pm 2.49$ & $2.12-11.17$ \\
\hline
\end{tabular}

aging an individual branch of the LFCN in dissections around the IL or anterior thigh is high in $26 \%$ of the cadavers. ${ }^{[8]}$ To protect the LFCN and its branches during interventions, a good knowledge of the localization and distribution of the LFCN in the region is required.

In the present study, we investigated localization of the LFCN in relation to ASIS and the IL in human fetuses. We also described the branching patterns of the LFCN.

Although there are several publications describing the anatomy of LFCN in adults, we did not encounter any studies on the course and branching pattern of the LFCN in human fetuses.

Since there were no previous studies on fetusus, we could compare our results with previous studies performed on adults. Uzel et al. ${ }^{[10]}$ described the location of the LFCN in relation to the ASIS. They found that all LFCNs passed medial to the ASIS and behind the IL as a single trunk. Kosiyatrakul et al ${ }^{[11]}$ found that $41.7 \%$ of the LFCNs cross over or proceed laterally to the ASIS. Murata et al., ${ }^{[12]}$ in their study on 205 sides, found that $58.5 \%$ of the nerves cross medially to the ASIS and $41.5 \%$ cross over or progress laterally to the ASIS. They classified the LFCN according to the position of the nerve in relation to the ASIS at the point where the nerve crossed over the iliac crest or under the IL: Type A, LFCN crossing over the iliac crest more than $2 \mathrm{~cm}$ posterior to the ASIS (2\%); Type B, LFCN crossing over the iliac crest within $2 \mathrm{~cm}$ posterior to the ASIS (10.8\%); Type C, LFCN crossing at the ASIS (28.8\%); Type D, LFCN crossing under the IL and ASIS (58.5\%). Murata et al. ${ }^{[12]}$ also classified LFCN according to its level of crossing the iliacus muscle: Type 1 : at a point $5 \mathrm{~cm}$ posterior to the ASIS; Type 2: within 3 $\mathrm{cm}$ of the iliac crest, $(8.9 \%)$ or Type 2 ( $>3 \mathrm{~cm}$ distant from the iliac crest $(91.1 \%)$. They noted that some nerves ran straight across the iliacus muscle, whereas others followed a convex or a concave curve. In our study, the location of the LFCN was not variable and it extended below the IL adjacently to the medial aspect of ASIS. We did not find any LFCN passing laterally to the ASIS or crossing anterior to the IL in our dissections. These findings are in accordance with those of Uzel et al., ${ }^{[10]}$ Hospodar et al., ${ }^{[4]}$ Doklamyai et al. ${ }^{[7]}$ and Ropars et al..${ }^{[1]]}$ but they are different from some previous reports. ${ }^{[8,11,12,14]}$

As in this study, multiple branches of the LFCN are reported by several studies. The highest number of branches for LFCN was four (2\%) in one extremity. In all of the previous studies, excluding the study of Doklamyai et al., ${ }^{[7]}$ classical two terminal branches pattern was observed as the most common branching type (64\%) (Table 3). Two branches (Type Ib) was the most common type), found in 54\% of our cases (Figure 1).

Table 3

The most frequent branching pattern (number of trunks and incidence - when stated) of the LFCN described in the literature.

\begin{tabular}{|c|c|c|c|c|c|c|c|}
\hline Reference & $\begin{array}{c}\text { Case } \\
\text { (n) }\end{array}$ & Material & $\begin{array}{c}\text { Branch (n) } \\
\text { Min-Max }\end{array}$ & One & Two & Three & Four \\
\hline Surucu et al. (1997)[3] & 44 & Adult cadaver & $1-4$ & $11.4 \%$ & $84 \%$ & $2.3 \%$ & $2.3 \%$ \\
\hline Doklamyai et al. $(2008)^{[7]}$ & 85 & Adult cadaver & $1-4$ & $75.3 \%$ & $21.2 \%$ & $2.3 \%$ & $1.2 \%$ \\
\hline Grothaus et al. $(2005)^{[8]}$ & 29 & Adult cadaver & $1-5$ & - & - & - & - \\
\hline Ropars et al. (2009) ${ }^{[13]}$ & 34 & Adult cadaver & $2-3$ & - & $94.1 \%$ & $5.9 \%$ & - \\
\hline Dias Filho et al. $(2003)^{[15]}$ & 52 & Adult cadaver & $2-3$ & - & $66 \%$ & $34 \%$ & - \\
\hline Zhang et al. (2010) & 20 & Adult cadaver & 2 & - & $100 \%$ & - & - \\
\hline This study & 50 & Fetus & $1-4$ & $14 \%$ & $64 \%$ & $20 \%$ & $2 \%$ \\
\hline
\end{tabular}




\section{Conclusion}

To our knowledge, this is the first study describing the morphological features and variations of the LFCN in human fetuses and provides understanding of its variability to guide further studies in this region.

\section{References}

1. Moore KL. Clinically oriented anatomy. 3rd ed. Baltimore: Williams and Wilkins; 1992. p. 385.

2. Standring S, editor. Gray's anatomy: the anatomical basis of clinical practice. 39th ed. New York (NY): Churchill Livingstone; 2005. p. 1126.

3. Surucu HS, Tanyeli E, Sargon MF, Karahan ST. An anatomic study of the lateral femoral cutaneous nerve. Surg Radiol Anat 1997;19: $307-10$.

4. Hospodar PP, Ashman ES, Traub JA. The anatomy of the lateral femoral cutaneous nerve, with special reference to the harvesting of iliac bone graft. J Orthop Trauma 1999;13:17-9.

5. Matta JM. Operative treatment of acetabular fractures through the ilioinguinal approach: a 10-year perspective. J Orthop Trauma 2006; 20:20-9.

6. Macnicol MF, Thompson WJ. Idiopathic meralgia paresthetica. Clin Orthop Relat Res 1990;254:270-4.

7. Doklamyai P, Agthong S, Chentanez V, Huanmanop T, Amarase C, Surunchupakorn P, Yotnuengnit P. Anatomy of the lateral femoral cutaneous nerve related to inguinal ligament, adjacent bony landmarks, and femoral artery. Clin Anat 2008;21:769-74.
8. Grothaus MC, Holt M, Mekhail AO, Ebraheim NA, Yeasting RA. Lateral femoral cutaneous nerve: an anatomic study. Clin Orthop Relat Res 2005;164-8.

9. Massey EW. Meralgia paresthetica secondary to trauma of bone graft. J Trauma 1980;20:342-3.

10. Uzel M, Akkin SM, Tanyeli E, Koebke J. Relationships of the lateral femoral cutaneous nerve to bony landmarks. Clin Orthop Relat Res 2011;469:2605-11.

11. Kosiyatrakul A, Nuansalee N, Luenam S, Koonchornboon T, Prachaporn $\mathrm{S}$. The anatomical variation of the lateral femoral cutaneous nerve in relation to the anterior superior iliac spine and the iliac crest. Musculoskelet Surg 2010;94:17-20.

12. Murata Y, Takahashi K, Yamagata M, Shimada Y, Moriya H. The anatomy of the lateral femoral cutaneous nerve, with special reference to the harvesting of iliac bone graft. J Bone Joint Surg Am 2000;82:746-7.

13. Ropars M, Morandi X, Huten D, Thomazeau H, Berton E, Darnault P. Anatomical study of the lateral femoral cutaneous nerve with special reference to minimally invasive anterior approach for total hip replacement. Surg Radiol Anat 2009;31:199-204.

14. Aszmann OC, Dellon ES, Dellon AL. Anatomical course of the lateral femoral cutaneous nerve and its susceptibility to compression and injury. Plast Reconstr Surg 1997;100:600-4.

15. Dias Filho LC, Valença MM, Guimarães Filho FA, Medeiros RC, Silva RA, Morais MG, Valente FP, França SM. Lateral femoral cutaneous neuralgia: an anatomical insight. Clin Anat 2003;16:309-16.

16. Zhang Q, Qiao Q, Gould LJ, Myers WT, Phillips LG. Study of the neural and vascular anatomy of the anterolateral thigh flap. J Plast Reconstr Aesthet Surg 2010;63:365-71.

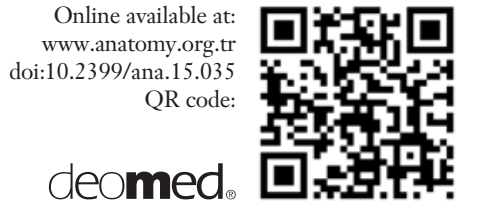

Correspondence to: Zeliha Fazlıoğulları, PhD Department of Anatomy, Faculty of Medicine, Selcuk University, 42130, Konya, Turkey

Phone: +90332 2243847

e-mail: z_topal@yahoo.com

Conflict of interest statement: No conflicts declared.

This is an open access article distributed under the terms of the Creative Commons Attribution-NonCommercial-NoDerivs 3.0 Unported (CC BY-NCND3.0) Licence (http://creativecommons.org/licenses/by-nc-nd/3.0/) which permits unrestricted noncommercial use, distribution, and reproduction in any medium, provided the original work is properly cited. Please cite this article as: Fazlıŏulları Z, Uysal İ̈, Ünver Doğan N, Karabulut AK, Ziylan T. An anatomic study of the lateral femoral cutaneous nerve in human fetuses. Anatomy 2016;10(1):16-20. 